\title{
Sexual isolation between Drosophila melanogaster females and Drosophila simulans males. I - Relation between homospecific and heterospecific mating success.
}

\author{
Maria C. CARRACEDO and P. CASARES \\ Departamento de Genetica, Universidad de Oviedo, Julian Claveria, s/n 33006 Oviedo, Spain
}

\begin{abstract}
Summary
The mating performances of $D$. melanogaster females and $D$. simulans males have been examined in homospecific and heterospecific crosses. Isofemale lines of $D$. melanogaster and $D$. simulans selected according to their previous high, intermediate, and low hybridization values in crosses between melanogaster females and simulans males were used. The dynamics of mating success as flies reached sexual maturity was examined. Female sexual maturity of the isofemale lines, estimated from mating frequency, gradually increased with ageing. Around 10 p. 100 of females were sexually mature in the first $24 \mathrm{hr}$ and the maximum value was attained roughly at day 3. Important differences in the speed of sexual maturity were found between the $D$. melanogaster lines. In $D$. simulans, differences between lines were small. Hybridization was not restricted to young females, as adults also hybridized on day 4 of life. In this sense, females played a more important role than males. Notably, the hybridization success of $D$. melanogaster females was directly related with their speed in attaining sexual maturity. However, no relation was found in $D$. simulans males between their hybridization success and their mating behaviour with homospecific females. Sexual isolation and mating propensities are discussed in the light of current mating theories.
\end{abstract}

Key words : Sexual isolation, mating success, sexual maturity, Drosophila melanogaster, Drosophila simulans.

\section{Résumé}

Isolement sexuel entre femelles Drosophila melanogaster et mâles Drosophila simulans : relation entre réussites d'accouplements homospécifiques et hétérospécifiques

L'aptitude à l'accouplement au sein de l'espèce d'une part (croisements homospécifiques) et entre espèces d'autre part (croisements hétérospécifiques) a été analysée pour des femelles de Drosophila melanogaster et pour des mâles de Drosophila simulans. Les souches utilisées provenaient de lignées isofemelles préalablement sélectionnées pour une aptitude à l'accouplement basse, moyenne ou élevée lors du croisement femelles melanogaster et mâles simulans. La dynamique de l'aptitude à l'accouplement en fonction de l'âge a été examinée ; la maturité sexuelle des femelles des lignées isofemelles, estimée à partir de la fréquence des accouplements, augmente graduellement avec lâge. Environ $10 \mathrm{p}$. 100 des femelles sont sexuellement matures dans les premières 24 heures et la valeur maximum est atteinte vers le $3^{\mathrm{e}}$ jour. Mais, alors que d'importantes différences de vitesse de maturation sont constatées entre lignées de $D$. melanogas- 
ter, ces différences sont faibles entre lignées de $D$. simulans. L'hybridation n'est pas limitée aux jeunes femelles puisque les adultes s'hybrident aussi au $4^{\mathbf{C}}$ jour de leur vie. Dans ce sens, les femelles jouent un rôle plus important que les mâles. En particulier, le succès de l'hybridation des femelles de $D$. melanogaster est directement lié à leur vitesse de maturation sexuelle. Cependant, chez les mâles $D$. simulans, on n'a pas trouvé de relation entre la réussite de l'hybridation et leur comportement en accouplement homospécifique. L'isolement sexuel et l'aptitude à l'accouplement sont discutés à la lumière des théories actuelles.

Mots clés : Isolement sexuel, réussite de l'accouplement, maturité sexuelle, Drosophila melanogaster, Drosophila simulans.

\section{Introduction}

The possibility of interspecific hybridization between $D$. melanogaster and $D$. simulans is known from the earliest works of STURTEvant (1920). Since then, it has been repeatedly observed that hybridization in the laboratory is negligible if the male is $D$. melanogaster, but a high frequency can occur when the male is $D$. simulans (PonteCoRvo, 1942 ; MANNING, 1959 ; BARKER, 1967). In the latter case, hybridization may be as high as 69 p. 100 (Watanabe, personal communication ; Carracedo and Casares, 1985a). In these studies, as a rule, males and females of different species are confined in a receptacle for a given time, with no mating choice between species. In crosses between melanogaster females and simulans males, intraspecific (PARSONS, 1972 ; WATANABE et al., 1977) and intrapopulational (CARRACEDo and CASARES, 1985a) variation in hybridization has been demonstrated. One important factor is the age of the individuals. All studies on this topic found greater hybridization if melanogaster females are aged for 1 day than for 3 or more days. The greater success of young females, despite their low general receptivity, led MANNING (1959) to suggest that a speciesspecific key for discrimination and sexual isolation, absent in young females, could develop with age. Mature females could effectively discriminate and interspecific mating become uncommon. The opposite would be true for young females which could mate with some persistent simulans males.

Another explanation for age-dependent hybridization is that if young males and females are placed together for several days and they mature in proximity, some type of habituation may develop, they become accustomed to each other and mating is facilitated once sexual maturity is reached.

In previous experiments we used adults aged 6 hours which remained together for 5 days (Casares \& Carracedo, 1985) or 10 days (Carracedo \& Casares, 1984 ; 1985a), the melanogaster females being examined for hybridization at the end of these periods of time. This procedure does not show if hybridization only occurred when females were young or if hybridization progressively increased with time due to persistent male courtship and increased female receptivity.

MANNING's explanation and the habituation hypothesis can both be applied to the results of our work (CARRACEdo \& CASARES, 1985a) on intrapopulational variation in hybridization between melanogaster females and simulans males, since we do not know whether the observed variation was due to variation in female species discrimination or whether it was originated through variations in male virility and female receptivity. In order to gain some knowledge on this point and the dynamics of the hybridization as time progressed, we carried out the present work. We selected some isofemale lines of 
D. melanogaster and D. simulans which had shown high, intermediate and low hybridization values in Carracedo \& Casares (1985a). In these lines we tested the mating performances of melanogaster females and simulans males in homo- and heterospecific crosses. The dynamics of mating was examined leaving the flies together for different periods of time.

\section{Materials and methods}

Fourteen isofemale lines were chosen on the basis of high $(\mathrm{H})$, intermediate (I) and low (L) hybridization averages in previous work (CARRACEdo \& CASAREs, 1985a). These lines (table 1) were employed to carry out 2 types of crosses : (1) Homospecific crosses in which males and females were paired in all the possible intra- and inter-line combinations ; (2) Heterospecific crosses, in which lines of $D$. melanogaster were used as females and paired with lines of $D$. simulans as males. Therefore, all crosses were performed by the "no-choice" method.

\section{TABLE 1}

Isofemale lines of $\mathrm{D}$. melanogaster and $\mathrm{D}$. simulans used in the present work, showing the hybridization values found in CARRACEDO \& CASARES (1985a).

\begin{tabular}{c|c|c|c}
\hline D. melanogaster lines & Hybridization & D. simulans lines & Hybridization \\
\hline MH1 & $35.0 \%$ & SH1 & $32.1 \%$ \\
MH2 & $27.1 \%$ & SH2 & $30.3 \%$ \\
MI1 & $21.4 \%$ & SI1 & $17.9 \%$ \\
MI2 & $16.4 \%$ & SI2 & $14.5 \%$ \\
MI3 & $21.2 \%$ & SI3 & $20.0 \%$ \\
ML1 & $9.6 \%$ & SL1 & $11.7 \%$ \\
ML2 & $10.0 \%$ & SL2 & $11.4 \%$ \\
\hline
\end{tabular}

The experiments were started with 2-h-old virgin adult flies. Five individuals of each sex with no obvious morphological defects were put into a culture vial $(25 \times 120 \mathrm{~mm})$ with standard baker's yeast food, in which they remained together for various periods of time. At the end of each time, the females were individually placed into vials in which the appearance of larval progeny was taken as evidence of fertile homo- or hetero-specific mating. The per vial mating average was computed as the number of females out of five leaving progeny.

Two experiments were run on different dates. Experiment 1 was performed with the MH1, MI1, and ML1 melanogaster lines and the SH1, SI1, and SL1 simulans lines. In this experiment the 5 pairs of flies were removed from vials after remaining together for $1,2,3,4$ or 5 days. In this way, 2 homospecific and 1 heterospecific $3 \times 3$ line crosses were carried out for each of the 5 different coexistence periods. There were 5 replicate vials for each of the 135 different tests. The handling of such a great volume 
of flies obliged us to limit the number of isofemale lines of each species to be examined (3), even though a higher number would have been desirable.

Results of Experiment 1 showed that (i) homospecific matings did not increase beyond 3 days of coexistence, and (ii) interspecific mating did not occur at all during the first 24 hours. For these reasons, only 3 different peiods of time were employed in Experiment 2. The 5 pairs of flies were removed from vials after 1, 2, or 3 days in the homospecific crosses, whereas in the heterospecific ones, the flies were removed after 2,3 , or 4 days. This reduction in the number of periods of time enabled us to examine 4 lines of each species in Experiment 2, namely, MH2, MI2, MI3, and ML2 for D. melanogaster, and SH2, SI2, SI3, and SL2 for D. simulans. There were 7 replicate vials for each test. All experiments were done at room temperature.

Some misconceptions may arise with the use of expressions related with " adult age " (CARRACEDo \& CASARES, 1985b) : briefly, observations made " on day 3 " of the fly's life, for example, are not at the same time as observations made with flies previously "aged for 3 days". In the latter, observations are clearly made " on day 4 ». In the future we will utilize the first expression.

\section{Results}

\section{A. Experiment 1}

Table 2 shows the average percentages of females leaving progeny for each of the 5 periods of time in which flies remained together. Each percentage is based on 5 replicate vials and therefore, on 25 females. Percentages were transformed by the arcsine function, corrected for small size as suggested by SNEDECoR \& Cochran (1967), and subjected to separate analyses of variance for each day. Lines of males and females were the sources of variation. Because no hybridization occurred on day 1 , analysis of variance for this period was not performed.

\section{Homospecific crosses}

In the $D$. melanogaster male $\times$ female crosses, the analyses of variance showed different effects for each sex (table 3 ). On day 1 , in which the number of matings was small, only effects derived from the different male lines were found. On days 2 and 3 differences between males disappeared, whereas female lines played a more decisive role in mating success. The maximum frequency of matings was attained roughly on day 3 and more time did not increase the percentage of matings. No differences between lines were observed on days 4 and 5 , showing that the lines were not different in maximum receptivity. Therefore, the between-line differences found on day 2 reflect differences in the speed of female sexual maturation : respectively 73 p. 100,80 p. 100 and 47 p. 100 mated for the female lines MH1, MI1 and ML1.

In the other homospecific cross, $D$. simulans male $\times$ female, the only significant $F$ value was the male $\times$ female interaction detected on day 2 . Thus, the three lines analyzed showed similar male and female performances in mating success. A few matings were scored on day 1 , but around 80 p. 100 of the females mated on day 2 . The comparison of this value with those of $D$. melanogaster indicated that sexual maturity was reached sooner for $D$. simulans than for $D$. melanogaster. 


\begin{tabular}{|c|c|c|c|c|c|c|}
\hline 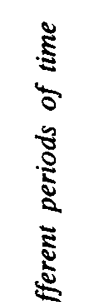 & 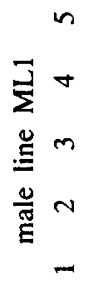 & 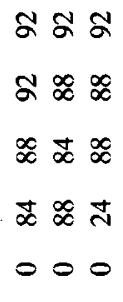 & 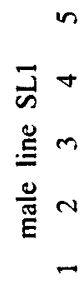 & 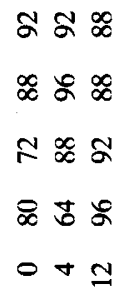 & 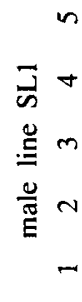 & 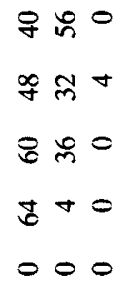 \\
\hline 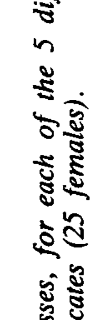 & $\begin{array}{c}n \\
\sum_{0}+ \\
\stackrel{\Xi}{E} m \\
\frac{0}{\tilde{E}} \sim \\
-\end{array}$ & 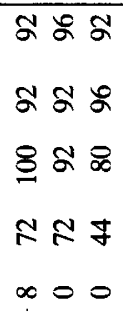 & 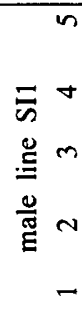 & 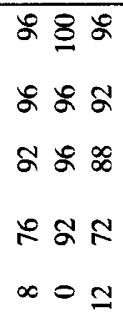 & 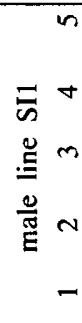 & 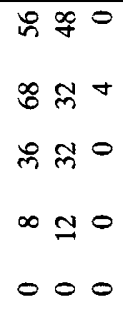 \\
\hline 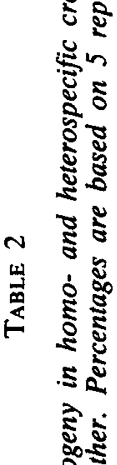 & 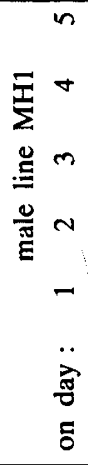 & 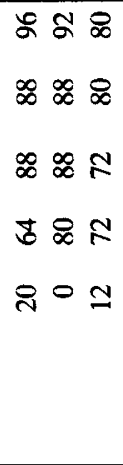 & 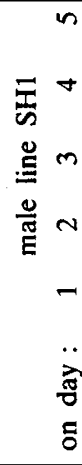 & 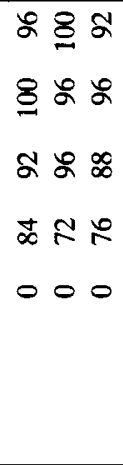 & 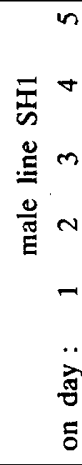 & $\begin{array}{l}\infty \forall+ \\
\mathbb{\infty} \approx \infty \\
i \simeq 0 \\
0+0 \\
000\end{array}$ \\
\hline 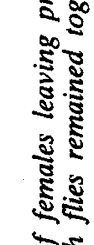 & & 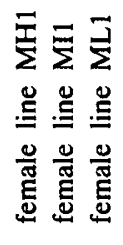 & & 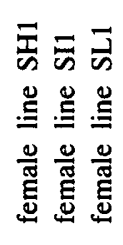 & & 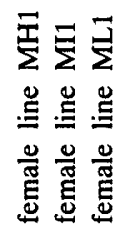 \\
\hline 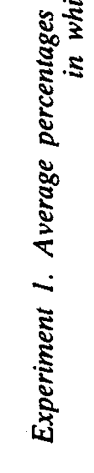 & & 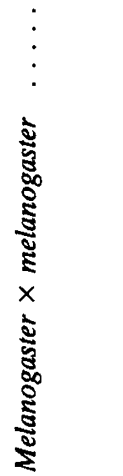 & & 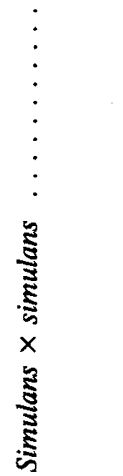 & & 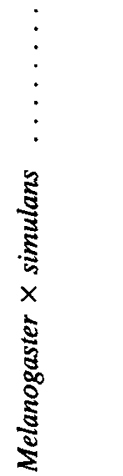 \\
\hline
\end{tabular}




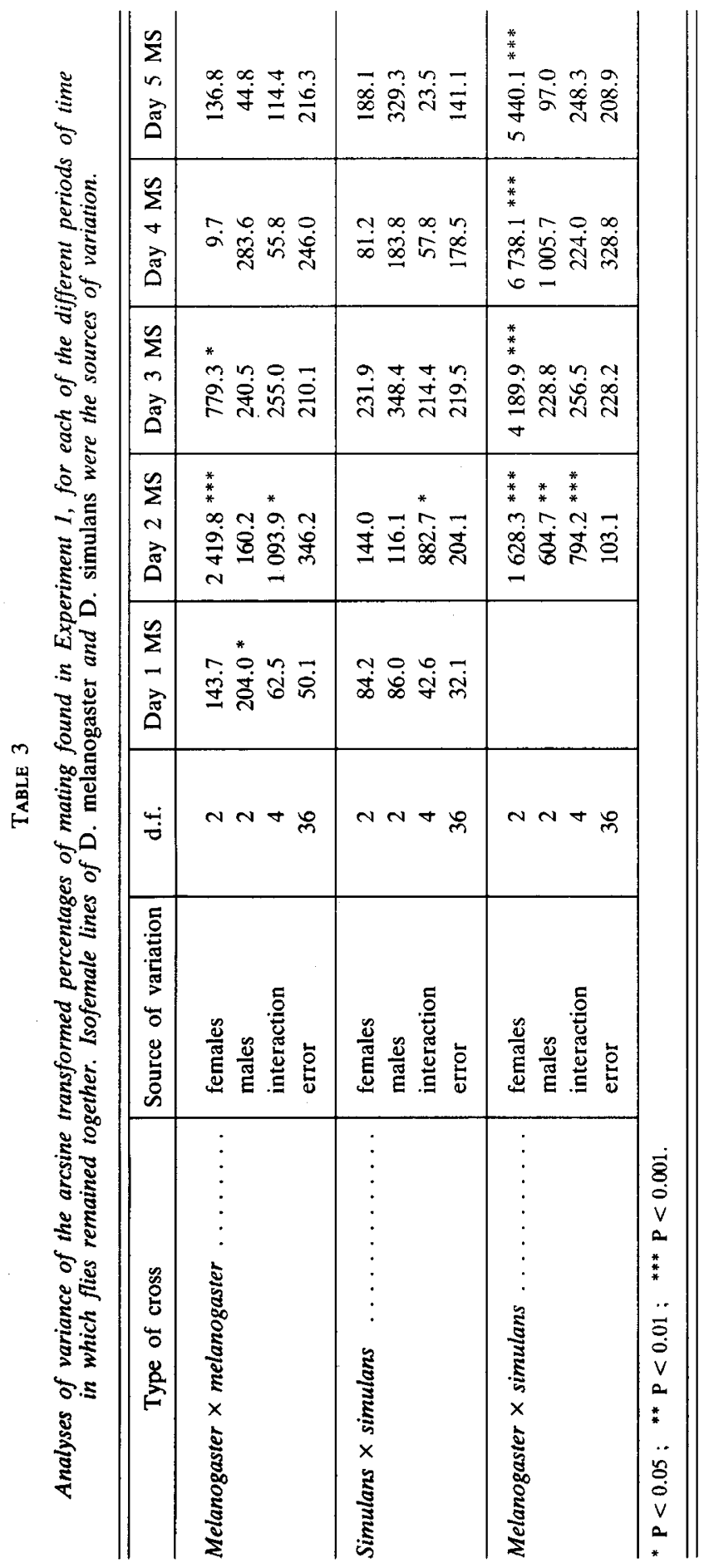




\section{Heterospecific crosses}

No matings were detected on day 1 . Hybridization was infrequent on day 2 , the maximum value being attained on day 4 of coexistence. Male lines of $D$. simulans showed a significant effect on hybridization only on day 2 , in which male $\times$ female interaction was important. However, on days 3,4 , and 5 only the female lines of $D$. melanogaster were important in deciding interspecific mating. Between-line differences were very important. The female maximum hybridization averaged over days 4 and 5 was 61 p. 100,44 p. 100 , and 3 p. 100 in lines MH1, MI1, and ML1 respectively, percentages which were parallel with the hybridization values on the basis of which the $H$, I, and L lines were previously selected for (table 1).

\section{B. Experiment 2}

The average percentages of females leaving progeny appear in table 4 . Percentages are based on 7 replicates and therefore on 35 females. Table 5 gives the results of analyses of variance of the transformed percentages for each of the three different periods of time.

\section{Homospecific crosses}

In the crosses between lines of $D$. melanogaster, the analyses indicated significant differences between both the male and female lines. Both sexes played, therefore, an important role in deciding mating. On day 1 , the percentages of mating were 19 p. 100 , 9 p. 100,8 p. 100 , and 2 p. 100 respectively for the MH2, MI2, MI3 and ML2 female lines. Clear differences were also evident on day 2 , with values of 79 p. 100, 73 p. 100 , 67 p. 100 , and 60 p. 100 . Therefore, between-line differences were observed and these were parallel on days 1 and 2. Differences tended to disappear on day 3 indicating that the lines of $D$. melanogaster had a different speed in reaching sexual maturity, a result already noticed in Experiment 1.

Differences due to males were not found in the crosses between the $D$. simulans lines. Thus, no relation was apparent between the mating performance of the $D$. simulans males with their own females and the hybridization frequency shown by these males in Carracedo \& Casares (1985a). Significant effects were found between females only on days 1 and 2 , as well as an important male $\times$ female interaction. The percentages of female mating for the SH2, SI2, SI3, and SL2 lines were 17 p. 100,19 p. 100, 34 p. 100 , and 21 p. 100 respectively, on day 1 ; and 66 p. 100,74 p. 100,77 p. 100 , and 81 p. 100 on day 2 . These are slightly higher than those found in the same periods for $D$. melanogaster, which indicates that female receptivity develops faster for $D$. simulans than for its sibling species. 


\begin{tabular}{|c|c|c|c|c|c|c|}
\hline 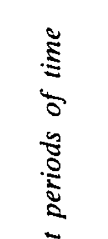 & 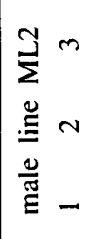 & 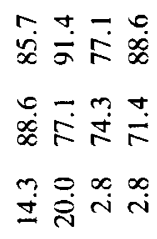 & 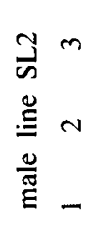 & 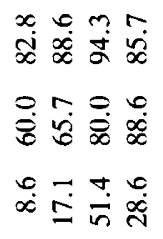 & 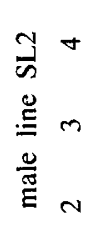 & 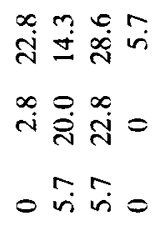 \\
\hline 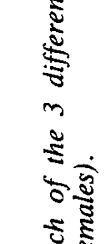 & 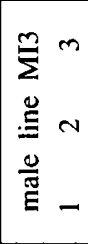 & 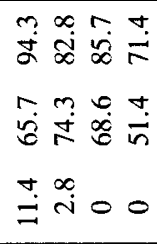 & 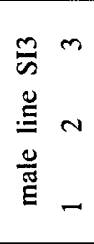 & 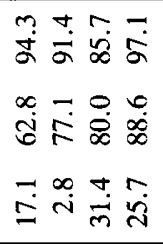 & 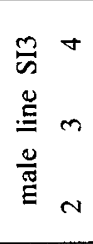 & 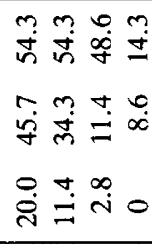 \\
\hline 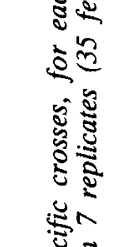 & 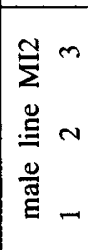 & 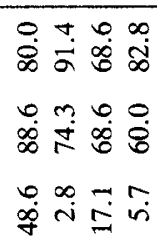 & 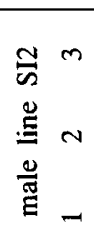 & 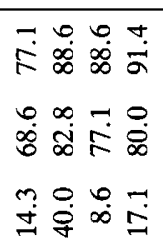 & 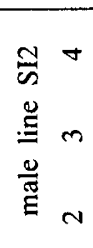 & 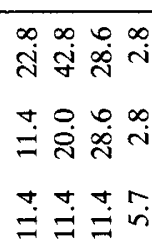 \\
\hline 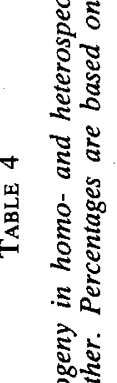 & 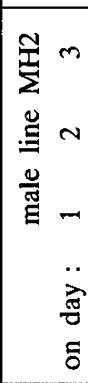 & 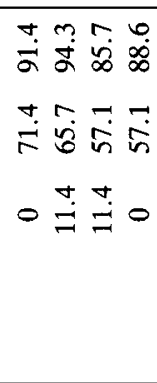 & 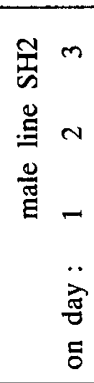 & 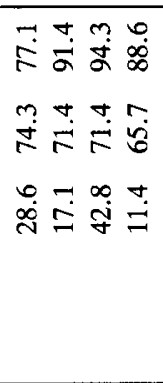 & 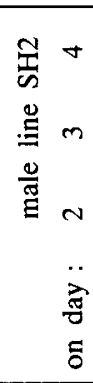 & 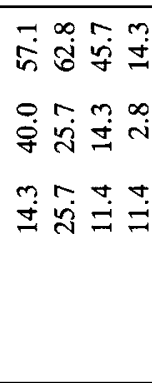 \\
\hline 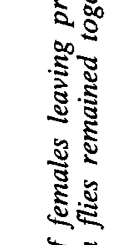 & & 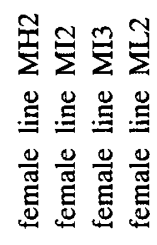 & & 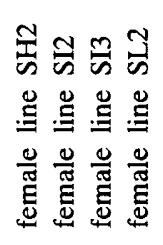 & & 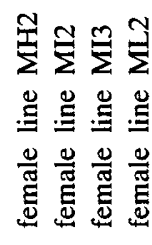 \\
\hline 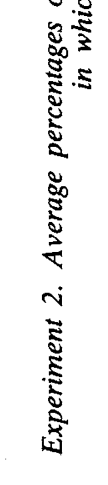 & & 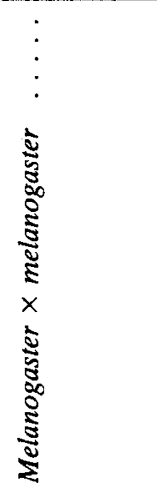 & & 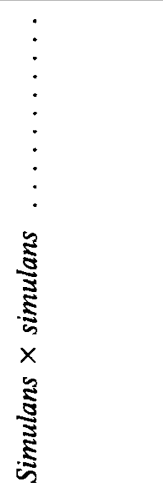 & & 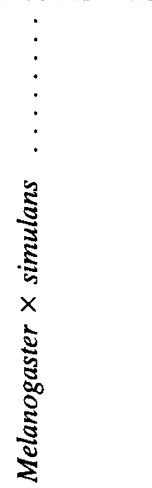 \\
\hline
\end{tabular}


TABLE 5

Analyses of variance of the arcsine transformed percentages of mating found in Experiment 2, for each of the different periods of time in which flies remained together.

Isofemale lines of $\mathrm{D}$. melanogaster and $\mathrm{D}$. simulans were the sources of variation.

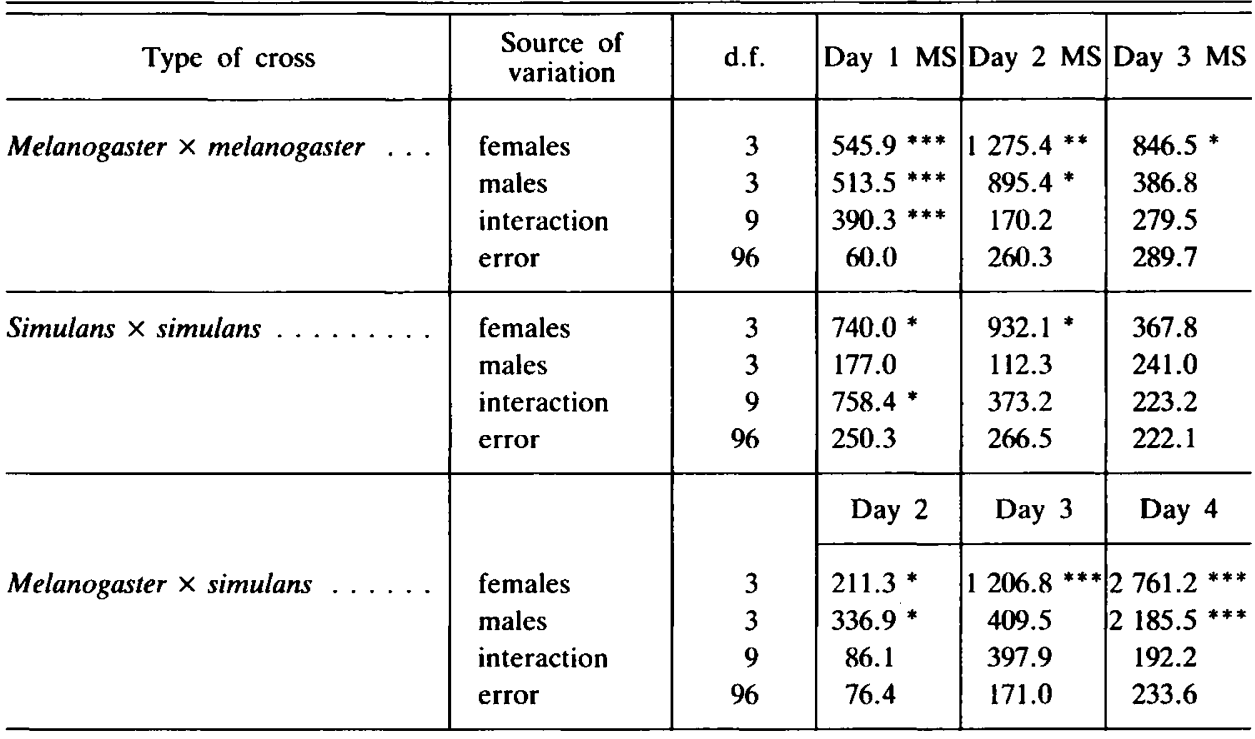

${ }^{*} \mathrm{P}<0.05 ;{ }^{* *} \mathrm{P}<0.01 ;{ }^{* * *} \mathrm{P}<0.001$.

\section{Heterospecific crosses}

Table 4 shows the average percentages of hybridized females. Hybridization was already important on day 2, but it increased on day 3 and also on day 4 of coexistence of melanogaster females and simulans males. The average of female maximum hybridization was 39 p. 100,43 p. 100,38 p. 100 , and 9 p. 100 for the lines MH2, MI2, MI3, and ML2 respectively. The corresponding analyses of variance (table 5) show clear and significant differences among lines of males and among lines of females, which emphasizes the important role that both sexes play in hybridization success. Male $\times$ female interaction was never observed, the performance of all the lines being very homogeneous. This is shown in table 4 , where it can be observed that, for example, line ML2 shows the minimum value of hybridization regardless of which $D$. simulans line is considered. Another example is line SH3, which shows the highest hybridization independent of the $D$. melanogaster line considered.

Some data in tables 2 and 4 deserve attention. For example, in the crosses melanogaster $\times$ melanogaster, $\mathrm{MH} 2$ females did not accept $\mathrm{MH} 2$ males on day 1 . Two explanations could be : (1) Females were unreceptive on day 1. (2) Males were immature on day 1 . Both explanations can be discarded since some $\mathrm{MH} 2$ females proved to be receptive with other males on this day (48 p. 100 mating with MI2 males) and, likewise, some MH2 males were able to mate with other females (11.4 p. 100 
mating with MI2 or MI3 females). Similarly, in the simulans $\times$ simulans crosses only $2 \mathrm{p}$. 100 mating occurred on day 1 between SI2 females and SI3 males, but some SI2 females were receptive with SI2 males $(40 \mathrm{p}$. 100) on the same day, and as well, some SI3 males mated with SI3 females (31 p. 100). These and other similar cases in tables 2 and 4 show that (i) females cannot be classified as receptive or unreceptive on the basis of one male line only, and (ii) females showed a low receptivity level on day 1 , and only those males providing enough courtship attained mating. This suggests that female receptivity slowly increases with age, more courtship being necessary when they are young.

We were interested in examining the possible relation between the homo and heterospecific mating performances of $D$. simulans male lines and $D$. melanogaster female lines. In $D$. simulans, no relation was detected between the percentage of male homospecific mating and the percentage of hybridization with $D$. melanogaster females. This was so because of the absence of between-line differences in homospecific crosses in contrast to the big differences these lines showed in heterospecific crosses.

TABLE 6

Mean numbers and percentages of $\mathrm{D}$. melanogaster females fertilized by homo- or heterospecific male lines found after different periods of coexistence. Numbers and percentages are based on 75 females for the MHI, MII, and MLI lines and on 140 females for the $M H 2, M I 2, M 13$, and $M L 2$ lines.

\begin{tabular}{|c|c|c|c|c|c|c|c|c|c|c|}
\hline \multirow{3}{*}{$\begin{array}{l}\text { Lines } \\
\text { MH1 }\end{array}$} & \multicolumn{4}{|c|}{ Homospecific matings } & \multicolumn{6}{|c|}{ Heterospecific matings } \\
\hline & \multicolumn{2}{|c|}{$\begin{array}{c}\text { Day } 2 \\
\text { number }(\%)\end{array}$} & \multicolumn{2}{|c|}{$\begin{array}{c}\text { Day } 3 \\
\text { number }(\%)\end{array}$} & \multicolumn{2}{|c|}{$\begin{array}{c}\text { Day } 2 \\
\text { number }(\%)\end{array}$} & \multicolumn{2}{|c|}{$\begin{array}{c}\text { Day } 3 \\
\text { number }(\%)\end{array}$} & \multicolumn{2}{|c|}{$\begin{array}{c}\text { Day } 4 \\
\text { number }(\%)\end{array}$} \\
\hline & 55 & 73.3 & 69 & 92.0 & 22 & 29.3 & 38 & 50.7 & 50 & 66.7 \\
\hline MI1 & 60 & 80.0 & 66 & 88.0 & 5 & 6.7 & 20 & 26.7 & 29 & 38.7 \\
\hline ML1 & 37 & 49.3 & 60 & 80.0 & 0 & 0 & 0 & 0 & 4 & 5.3 \\
\hline MH2 & 110 & 78.6 & 123 & 87.8 & 16 & 11.4 & 35 & 25.0 & 55 & 39.3 \\
\hline MI2 & 102 & 72.8 & 126 & 90.0 & 19 & 13.6 & 35 & 25.0 & 61 & 43.6 \\
\hline MI3 & 94 & 67.1 & 116 & 82.8 & 11 & 7.8 & 27 & 19.3 & 53 & 37.8 \\
\hline ML2 & 84 & 60.0 & 111 & 79.3 & 6 & 4.3 & 5 & 3.6 & 13 & 9.3 \\
\hline
\end{tabular}

With respect to the $D$. melanogaster lines, table 6 shows the percentages of homoand heterospecific matings, averaging the male lines, for certain periods of time. It is clear that ML1 and ML2 lines with the slowest female sexual maturity also show the smallest hybridization frequency which argues for a positive relationship between these 2 characteristics. Given that percentages for 3 of the 7 lines were obtained from Experiment 1 and for the other four from Experiment 2, the analysis of values of the 7 lines as a single set of data does not seem to be very appropriate. We assume, however, that any female line had been faced and measured against a very similar array of male lines (table 1) and therefore the 7 lines could cautiously be considered and analyzed as homogeneous data. In support of this, the comparison between the number of hybridizing females in Experiment 1 (162 out of $450 ; 36.0$ p. 100 obtained from days 4 and 5) and Experiment 2 (182 out of $560 ; 32.5$ p. 100 ; obtained from day 4) 
did not differ significantly ( $\chi_{i}^{2}=1.36$; not significant). So, we calculated correlations between the percentages of homo- and heterospecific matings for the 7 melanogaster lines. Since percentages were based on different number of females (table 6) weighted correlations were computed in which each percentage received a weight equal to its variance. As correlations were mostly significant (table 7), it can be concluded that the percentage of hybridization of $D$. melanogaster female lines is directly related with the speed of sexual maturation of the lines.

\section{TABLE 7}

Coefficients of correlation ( $r$ ) between the percentages of mating with homo- and heterospecific males shown by the $7 \mathrm{D}$. melanogaster female lines, at different periods of time.

\begin{tabular}{c|c|l}
\hline Homospecific & Heterospecific & \multicolumn{1}{|c}{$\mathbf{r}(5 \mathrm{df})$} \\
\hline Day 2 & Day 2 & $0.55($ not significant $)$ \\
Day 2 & Day 3 & $0.76(\mathrm{P}<0.05)$ \\
Day 2 & Day 4 & $0.77(\mathrm{P}<0.05)$ \\
Day 3 & Day 2 & $0.81(\mathrm{P}<0.05)$ \\
Day 3 & Day 3 & $0.90(\mathrm{P}<0.05)$ \\
Day 3 & Day 4 & $0.89(\mathrm{P}<0.05)$ \\
\hline
\end{tabular}

\section{Discussion}

It is important to bear in mind that our results deal with the number of matings in homo- and heterospecific tests. Mating is a complex reciprocal male-female interaction based on male and female mating propensities. All visible signals and rituals that constitute normal courtship in Drosophila (male latency, wing vibration, duration of courtship, female sex-appeal) have not been taken into consideration in the present paper. Therefore, when considering heterospecific matings we are only concerned with the breakdown of sexual isolation and in this way we ignore the premating isolation mechanisms.

We see mating as a function of (i) a potential condition and (ii) an effective situation: (i) Male sexual virility is the ability to display a normal and intense male courtship in which age, physiological state, and genetic determinants, among other factors, are involved. Female receptivity is the female ability both to accept males and to display normal sexual behavior in which age, physiological state, and genetic determinants, among other factors, are involved. (ii) For both the male and the female, the effective situation occurs only when a male or female receives the appropriate stimuli in a given sequence, which are necessary for their own normal sexual behaviour. These stimuli include tactile, olfactory, auditory and visual cues (see SPIETH \& Ringo, 1983). The stimuli provided by one sex (sometimes called "sex appeal ») determine behavioural responses in the opposite sex which, in turn, are stimuli for the former.

Young flies are sexually immature. Sexual maturation is the process during which males and females develop mating ability. MANNING (1967) suggested that the change of 
unreceptive to receptive females is both a sudden and an all-or-nothing process, and from direct observations of courtship and mating during 30 minutes, he also pointed out the period within 24-48 hours as the age at which melanogaster and simulans females attained receptiveness. Our data do not support these points. The number of matings as time progresses supplied information about the development of sexual maturity and so, males and females of $D$. melanogaster or $D$. simulans aged less than 24 hours achieved a great deal of fertile matings (tables 2 and 4) with values close to 50 p. 100 in some crosses. On the other hand, we think that female receptivity increases with age in a progressive way. This was first suggested by MANNING (1959) in D. melanogaster and D. simulans females, and later, CоOK (1973) conclusively demonstrated that once a female has become sexually mature, her receptivity gradually increases up to a maximum level on day 3 after eclosion. Our results support this : (i) Our melanogaster lines reached sexual maturity with different speeds. (ii) Within each line, the number of females accepting a given type of male slowly increased during the first $48 \mathrm{~h}$. (iii) $D$. melanogaster females of a given line were apparently unreceptive on day 1 when tested with a male line although females from the same line and of the same age were receptive with another male line ; this suggests that although these females were mature on day 1 , they had low receptivity levels and only the more vigorous males were accepted. Clearly, these points do not agree with a sudden and all-or-nothing process for the occurrence of female receptivity.

D. simulans female receptivity seems to increase gradually also, although results are not so evident as for $D$. melanogaster. More matings occurred for $D$. simulans than for D. melanogaster in the first $24 \mathrm{~h}$ after eclosion which, similar to ManNING's (1959) results, indicated a faster sexual development for the $D$. simulans females.

The role that each sex plays in homospecific mating is different for the 2 species. In $D$. melanogaster, males are more important when flies are young, which confirms MANNING's (1959) findings. Indeed, if young females have little receptivity, as suggested above, differences in male maturation speed can be the origin of this result, since male courtship in $D$. melanogaster begins a few hours after adult emergence and increases in intensity as time progresses (EASTwOod \& BURNETT, 1977). Our results also show that as flies age, females assume a preponderant role in mating decisions, which supports the generally acepted theory that females decide homospecific mating whereas males court them rather indiscriminately (see review by SpIETH \& Ringo, 1983). In $D$. simulans results gave a different picture, for the lines analyzed showed no differences between female lines or between male lines.

When considering interspecific mating, some remarkable facts appear. That melanogaster females were not mated forcibly by simulans males was evident, for no heterospecific mating was recorded on day 1 although some melanogaster females proved to be receptive (with their own males) in this same period of time.

It is well known that the melanogaster $\times$ simulans mating occurs with relative ease if females are very young but it is very difficult if females are 3 or more days old (Pontecorvo, 1942 ; Manning, 1959 ; Barker, 1962 ; 1967 ; Parsons, 1972). In our experiment, hybridization started on day 2, but its frequency increased up to day 4 upon which maximum frequency of hybridization was attained. Moreover, it is evident that success in hybridization is not parallel with the development of sexual maturity: females of $D$. melanogaster showed maximum homospecific receptivity on day 3 , whereas on day 4, heterospecific mating still occurred. This result does not support MANNING's hypothesis (1959) on the ontogeny of the melanogaster-simulans sexual 
isolation. This author suggests the existence of a species-specific key in mature $D$. melanogaster females for recognition and discrimination against $D$. simulans males. Such a key (possibly a cuticular pheromone of melanogaster females) would be absent in young females, but its concentration would progressively increase with age, owing to which mature melanogaster females would not easily mate with simulans males. In support of MANNING's view, it has been noticed (see JALLON, 1984) that young melanogaster and simulans females have similar pheromones; but as flies age, the spectrum of melanogaster female sex pheromones is replaced by species-specific pheromones which are different from those of mature simulans females. This sex-appeal modulation might explain the greater success of simulans males with young versus mature melanogaster females.

In another widely suggested hypothesis, homo- or heterospecific mating occurs, as stated above, when a receptive female surpasses a certain level of excitation which is a function of the female's own mating propensity as well as the amount of appropriate courtship directed towards her. The fact that in our work heterospecific mating was not restricted to young melanogaster females, does not support the sudden release of a species-specific key in mature females ; on the contrary, a similar number of females hybridize on day 2 and on day 4 . It is more plausible that in our experiments, one (or both) of the simulans male and melanogaster female mating propensities had increased with age. On the other hand, our methodology imposes a long and constant cohabitation of both sexes and species in a single vial, and the possibility exists that some type of interspecies habituation may develop, increasing in this way the probability of interspecific matings. More work is obviously necessary to elucidate these results.

The lines used in our study were selected for their previous performances in hybridization (CARRACEDo \& CASARES, 1985a). These characteristics remained constant throughout experimentation in the melanogaster female and the simulans male lines. But it is worth noticing that the greater or lesser hybridization shown by the simulans male lines has no relation with the mating performances of these male lines with their own females. The above result is not easy to explain and there is no explanation at the present. It might be that hybridization is attained only by those simulans males courting melanogaster females more persistently, a suggestion needing further experimentation.

More interesting is the case for D. melanogaster females, in which success in hybridization, the breakdown of sexual isolation, is highly correlated with and basically depends on the speed with which melanogaster females develop their sexual maturity (measured with conspecific males). If this speed were directly correlated with receptivity (as unpublished results suggest), then highly receptive melanogaster females could have a high probability of interspecific mating. High female receptivity seems to be important in determining female fitness, but this might be disadvantageous if it is accompanied by an increase in the probability of hybridization. Merrell (1949) stated that high female receptivity is analogous to little discrimination.

If the influence of each sex in hybridization is examined, both the melanogaster female lines and the simulans male lines are of importance for breaking up sexual isolation. Even so, females are somewhat more important than males, a fact already stated by Parsons (1972), Carracedo \& Casares (1985a) and Casares \& Carracedo (1985). This result, based on interspecific matings, is in contradiction with SCHILCHER \& Dow (1977) who, basing their views on ethological observations (premating isolation), claimed the males to be primarily responsible for the melanogaster-simulans sexual isolation. But the possibility of mating in interspecific crosses cannot be deduced from 
the premating behaviour of one of the sexes only. For instance, the melanogaster male intensely courts simulans females but mating does not generally occur. The simulans male does not court (or only weakly) melanogaster females but mating frequency may be quite high. Therefore, in the pair $D$. melanogaster and $D$. simulans interspecific male courtship measured for a few minutes is not predictive of the possibility of a breakdown in their sexual isolation.

Certainly, although male courtship intensity seems to be function of female sexappeal (see TompKins, 1984), mating only occurs when a female attains the necessary excitation level for male acceptance. Thus, although females of some strains of $D$. simulans had a great sex-appeal for the melanogaster male (JALLON, 1984), no mating occurred, that is, the male's courtship was not enough to cause the necessary level of female receptivity. On the contrary, the sex-appeal of the melanogaster female must be small for the simulans male, given the little attention he shows towards her (MANNING, 1959 ; SCHILCher \& Dow, 1977 ; Wood \& Ringo, 1980). Despite this, some matings occur, possibly due to a high receptivity of melanogaster females towards simulans males. If correct, the above might explain why, in our results, the melanogaster female lines with fastest sexual maturity (and possibly greatest receptivity), are those with the highest frequency of hybridization.

It may be argued that in our study there is no " mating choice " between the 2 species, the precopulatory isolation mechanisms being partially suppressed, and therefore results are not very natural. Nevertheless, hybridization can also occur with relative high frequency under conditions of free choice in the laboratory (PrUZAN et al., 1979 ; Carracedo \& Casares, 1985c) as well as in nature, as noticed by Sperlich (1962), and we found this in flies of both species caught in the same traps (unpublished observations).

Received October 30, 1985.

Accepted July 18, 1986.

\section{Acknowledgements}

We would like to thank an anonymous reviewer for constructive criticisms of the manuscript which greatly improved the paper.

\section{References}

Barker J.S.F., 1962. Sexual isolation between D. melanogaster and D. simulans. Amer. Nat., 96, 105-115.

BARKer J.S.F., 1967. Factors affecting sexual isolation between D. melanogaster and D. simulans. Amer. Nat., 101, 277-287.

Carracedo M.C., Casares P., 1984. Estudio de la hibridacion entre $D$. melanogaster y $D$. simulans. Boletin Ciencias Nat. I.D.E.A., 33, 15-29.

Carracedo M.C., Casares P., 1985a. Intrapopulational genetic variation in the hybridization between $D$. melanogaster females and $D$. simulans males. Experientia, 41, 106-108. 
Carracedo M.C., Casares P., 1985b. A study on the dynamics of crossing between $D$. melanogaster females and D. simulans males. Drosophila Inf. Serv., 61, 42-43.

Carracedo M.C., Casares P., 1985c. Hybridization between D. melanogaster and D. simulans in competition experiments. Drosophila Inf. Serv. 61, 41-42.

Casares P., Carracedo M.C.. 1985. Hybridization between sympatric and allopatric populations of D. melanogaster and D. simulans. Drosophila Inf. Serv., 61, 43-44.

Cook R.M.. 1973. Physiological factors in the courtship processing of Drosophila melanogaster. J. Insect. Physiol., 19, 397-406.

Eastwood L., Burnetr B., 1977. Courtship latency in Drosophila melanogaster. Behav. Genet., 7, 359-372.

JALLON J.M., 1984. A few chemical words exchanged by Drosophila during courtship and mating. Behav. Genet., 14, 441-478.

Manning A., 1959. The sexual isolation between D. melanogaster and D. simulans. Anim. Behav., 7, 60-65.

Manning A., 1967. The control of sexual receptivity in female Drosophila. Anim. Behav., 15, 239-250.

Merrell D.J., 1949. Selective mating in D. melanogaster. Genetics, 34, 370-389.

PARSONS P.A., 1972. Variation between strains of $D$. melanogaster and $D$. simulans in giving offspring in interspecific crosses. Can. J. Genet. and Cytol., 14, 77-80.

Pontecorvo G., 1942. Age of females as determining the success of $D$. melanogaster $\times D$. simulans cross. Drosophila Inf. Serv., 16, 66.

Pruzan A., Ehrman L., Perelle I., Probber J., 1979. Sexual selection, Drosophila age and experience. Experientia, 35, 1023.

SCHILCHER F. Von, Dow M., 1977. Courtship behaviour in Drosophila : sexual isolation or sexual selection. Z. Tierpsych., 43, 304-310.

Snedecor G.W., Cochran W.G., 1967. Statistical Methods. 5th ed., 534 pp., Iowa St. University Press, Ames.

SPERLICH D., 1962. Hybrids between D. melanogaster and D. simulans in nature. Drosophila Inf. Serv., 36, 118.

SiETH H.T., Ringo J.M., 1983. Mating behavior and sexual isolation in Drosophila. In : AsHbURNer M., Carson H.L., Thompson J.N. Jr. (eds.), The Genetics and Biology of Drosophila, Vol. 3c, 224-284. Academic Press, London.

Sturtevant A.H., 1920. Genetic Studies on Drosophila simulans. I. Introduction. Hybrids with D. melanogaster. Genetics, 5, 488-500.

TompKins L., 1984. Genetic analysis of sex appeal in Drosophila. Behav. Genet., 14, 411-440.

Watanabe T.K., Lee W.H., Inoue Y., Kawanishi M., 1977. Genetic variation of the hybrid crossability between $D$. melanogaster and D. simulans. Jpn. J. Genet., 52, 1-8.

Wood D., Ringo J.M., 1980. Male mating discrimination in D. melanogaster, D. simulans and their hybrids. Evolution, 34, 320-329. 